\title{
Is Shakespeare a Foreign Language?
}

\author{
An Interview with Peadar Donohoe, Artistic Director of Cyclone Repertory \\ Company, Cork
}

Cyclone Repertory Company Ltd. is a core group of actors \& technicians based in Cork who are devoted to the art of theatre to serve the wider community through quality productions that entertain and educate.

More recently the company has been very successful in Ireland with performances of their 'pedagogic adaptations' of plays by William Shakespeare. Scenario readers may also wish to view short films which give a first impression of the unique way in which Cyclone have managed to make Shakespeare's texts accessible and interesting to Irish secondary school students.

The SCENARIO interview with Peadar Donohoe can be downloaded here For a short film on Cyclone's approach to Macbeth click here, for a short film on Hamlet click here 